\title{
Simulation of greenhouse energy use: an application of energy informatics
}

\author{
Richard T. Watson ${ }^{1 *}$ D, Marie-Claude Boudreau ${ }^{1}$ and Marc W. van lersel ${ }^{2}$
}

\author{
* Correspondence: rwatson@terry. \\ uga.edu \\ ${ }^{1}$ Department of Management \\ Information Systems, University of \\ Georgia, Athens, GA 30602-1575, \\ USA \\ Full list of author information is \\ available at the end of the article
}

\begin{abstract}
Greenhouse agriculture is a highly efficient method of food production that can greatly benefit from supplemental electric lighting. The needed electricity associated with greenhouse lighting amounts to about 30\% of its operating costs. As the light level of LED lighting can be easily controlled, it offers the potential to reduce energy costs by precisely matching the amount of supplemental light provided to current weather conditions and a crop's light needs. Three simulations of LED lighting for growing lettuce in the south-east of the US using historical solar radiation data for the area were conducted. Lighting costs can be potentially reduced by approximately $60 \%$.

Keywords: Controlled-environment agriculture, Horticulture, Supplemental lighting, Simulation, Energy efficiency
\end{abstract}

\section{Background}

In January 2007, the first two authors of this article started a project to link information systems (IS) scholarship to ecological sustainability. They were concerned that IS scholars were paying minimal attention to global warming and that they did not consider it a problem worthy of their attention. While leading scientists (Holdren 2009) were calling for their peers to spend $10 \%$ of their time solving the existential threat resulting from the burning of fossil fuels, IS scholars were generally ignoring the issue. Consequently, this important problem has remained a marginal IS research topic (Gholami et al. 2016; Malhotra et al. 2013). Since 2010, we have advocated for academic leaders (journal editors in particular) to embrace environmental sustainability as a core principle in the research they publish (Watson et al. 2010); the emergence of this journal constitutes a critical step in engaging more scholars in solving the problem of our time.

The project to engage IS scholars in sustainability scholarship resulted in a proposal to create Energy Informatics as a new field of IS research (Watson et al. 2010) (Watson and Boudreau 2011). Leveraging the Energy Informatics framework, we produced a case study on how one of the world's major logistic companies was applying the principles to reduce energy consumption and advance sustainability (Watson and Boudreau 2011). Energy efficiency, the invisible fuel, reduces the demand for fossil fuels and thus contributes to carbon emission reduction.

The Energy Informatics framework identifies the central elements of an energy supply and demand system, including the key stakeholders, the three major eco-goals, and the major social forces influencing an energy production/consumption system. The framework

(C) The Author(s). 2018 Open Access This article is distributed under the terms of the Creative Commons Attribution 4.0 International License (http://creativecommons.org/licenses/by/4.0/), which permits unrestricted use, distribution, and reproduction in any medium, provided you give appropriate credit to the original author(s) and the source, provide a link to the Creative Commons license, and indicate if changes were made. 
directs attention to flow networks, sensor networks, and sensitized objects as these are the source and destination of the necessary data inputs and outputs to advance energy efficiency through the use of information systems. The framework arose from reviewing many energy production/consumption systems, such as traffic congestion management and building energy management.

The principal observation is that economies consist of flow networks (e.g., cars, water, people, packages, containers) that consume energy. The management of the energy consumed by such flows requires sensor networks to provide digital data streams reporting on the current status of the flow network so that high quality decisions can be made about the status of sensitized objects that can control the flow network. Actions might be as simple as turning off a valve supplying hot air to a work space. They may also be remotely controlled, such as in the management of hundreds of traffic lights to reduce city traffic congestion.

The original Energy Informatics framework has proved robust because it identifies the main components of an energy flow network and the means of controlling them. It highlights the central role of an information system, linking the interdependencies between supply and demand and the major components (i.e., flow networks, sensor networks, and sensitized objects).

The Energy Informatics framework has been applied to multiple domains, such as road pricing, farming, logistics, bicycle sharing, and others. Recently, we have applied this framework to another major existential problem: food security.

\section{Food security}

Food security is a critical problem that demands the attention of IS scholars, as well as horticulturists, agricultural scientists, and others concerned with food production. Over the next 30 years, the world's population is predicted to grow by up to $34 \%$ and urbanization will increase by around $20 \%$. To feed this wealthier and larger population, food production must increase by an estimated 70\% (Food and Agriculture Organization of the United Nations 2009). Achieving food security by minimizing variations in supply and adjusting to the growth in food demand presents many challenges that will likely require a major adjustment in current agricultural practices (Magnin 2016). Food security could be enhanced by reducing personal meat consumption and shifting to a predominantly vegetarian diet, but this would require significant behavioral changes to well-established customs and practices. Our focus in this research is on modifying agricultural practices rather than promoting behavioral change.

\section{A solution}

Controlled-environment agriculture (CEA), such as indoor farms and greenhouses, is a key path to increasing food production. CEA can produce up to 20 times as much high-end, pesticide-free produce as a similar-size plot of soil but requires electric lighting to do so (Science Illustrated 2011). Such facilities will be necessary to meet the future demand for quality fruits and vegetables, particularly in China with its rapidly growing and large middle class (Science Illustrated 2011).

In 2016, the CEA market was dominated by Europe, Middle East, and Africa (EMEA), following by the Americas, and Asia Pacific, with percentage shares and values of $62 \%$, $23 \%$, and $15 \%$ of a market valued at USD 20.25 billion. The Netherlands, Spain, and Italy 
dominate EMEA production; in the Americas, horticulture is mainly in North America; and China has been growing rapidly with more than one million greenhouses. ${ }^{1}$

The smart greenhouse is emerging as a solution, offering various collections of integrated technologies in a greenhouse, to improve the productivity of CEA. The smart greenhouse vision is based on sensors, actuators, and monitoring and control system that can optimize plant growth and quality and automate the growing process. This market was valued at approximately USD 680.3 million in 2016 . With a short-term compound annual growth rate of around $14.12 \%$, it is expected to reach approximately USD 1.3 billion by $2022 .{ }^{2}$ At this stage, the smart greenhouse market is about $3 \%$ of the world market.

The greenhouse industry's current practices can require considerable energy to power electric lighting to maintain plant growth on overcast days, so as to meet production schedules. Electricity for lighting can make up to $30 \%$ of the costs for greenhouses (van Iersel MW, Gianino D: An adaptive control approach for LED lights can reduce the energy costs of supplemental lighting in greenhouses, Submitted). Currently, many commercial greenhouses use high intensity discharge (HID) lights, ${ }^{3}$ which have high output, cover wide areas, and emit high heat. These lights have timers or automated control systems that use sensors to turn on all lights at full power when natural light levels drop below a predetermined intensity, even when only a fraction of the light might be required to reach a crop's needs for growth. In the extreme, some growers might leave the lights on full power for a substantial portion of the day (as most plants need between 12 to $18 \mathrm{~h}$ of light per day, depending on the species). This approach to growing crops is inefficient, resulting in energy waste, higher operational costs, and often unnecessary carbon emissions.

Prior research to reduce CAE electricity costs by making greenhouses smarter has produced a variety of 'branded' solutions. Intelligrow (Aaslyng et al. 2003; Markvart et al. 2007), DynaLight (Kjaer et al. 2011, 2012) (Clausen et al. 2015), and DynaGrow (Sørensen et al. 2016) are successive developments of software for optimizing greenhouse production and minimizing energy costs. DynaGrow, the most recent and advanced of cumulative research in Danish greenhouses, applies multi-criteria methods to control a greenhouse's climate. The solution has been physically implemented through software and associated sensors and actuators within a greenhouse and produces savings of 64\% with LED lighting (Sørensen et al. 2016), the concern of this article.

The study reported in this article differs in several ways. First it is a simulation rather than a physical implementation. A key purpose is to identify the savings generated by adaptive LED lighting and what form of software as a service (SaaS) might be economically viable. Simulation enables inexpensive consideration of alternatives. Second, there is a single objective of minimizing electricity cost subject to ensuring that a crop receives sufficient light each day to meet growth needs for on time contract delivery. This research, like the Danish stream, is based on current knowledge of plant physiology.

\section{Plant physiology}

Plants grow by converting photons (sunshine or supplemental lighting), water, and $\mathrm{CO} 2$ to sugars $^{4}$ and oxygen. The environmental conditions and physiology of each plant determine the rate of photosynthesis. For the purposes of this research, we can think of a plant using photons to transport electrons. In the light reactions of photosynthesis, photons are absorbed by photosynthetic pigments, and the energy is used to transport electrons. This 
electron transport then results in the production of chemicals required for the synthesis of sugars. The electron transport rate (ETR) is a direct measure of the light reactions of photosynthesis in response to photosynthetic photon flux (PPF) (Fig. 1). ETR is the driving force for photosynthesis and ultimately crop growth. Both ETR and PPF are measured in micromoles ${ }^{5}$ per square meter per second $\left(\mu \mathrm{mol} \mathrm{m} \mathrm{m}^{-2} \mathrm{~s}^{-1}\right.$ of electrons and photons, respectively). The efficiency of the conversion of the energy of photons into electron transport varies by plant species, but in general we can represent this relationship as a saturation curve of the form ETR $=\mathrm{a} .\left(1-\mathrm{e}^{(-\mathrm{b} . \mathrm{PPF})}\right)$, where $\mathrm{a}$ and $\mathrm{b}$ vary by species. The fitted saturation curve for lettuce illustrates the nature of this relationship (Fig. 1). As the saturation curve shows, conversion of photons into electron transport is most efficient at low levels of PPF, which is an important consideration when electric lighting is used. Essentially, low levels of lighting for long periods are more energy efficient than high levels for short periods. Furthermore, supplemental light provided when sunlight levels are low will be used more efficiently than supplemental light provided when sunlight levels are high.

A plant needs to transport a threshold number of moles of electrons per day to optimize its growth. This is particularly important for commercial crops, which are usually grown under contract with a scheduled harvesting date and defined delivery volume. Based on experiments at the University of Georgia, it has been determined that lettuce, for example, needs to transport approximately $3 \mathrm{~mol} \mathrm{~m}^{-2} \mathrm{day}^{-1}$ of electrons. On a typical day, this rate of electron transport requires approximately $18 \mathrm{~mol}$ of photons $\mathrm{m}^{-2}$ day $^{-1}$. This is close to the recommended daily light level for year-round production of high-quality lettuce of $17 \mathrm{~mol} \mathrm{~m}^{-2}$ day $^{-1}$ (Both et al. 1994).

We can convert daily electron transport into a required level of photons per second, as follows:

\section{$\mathrm{D}=\mathrm{ETR}$ in moles $\mathrm{m}^{-2}$ day $^{-1}$ to maximize growth}

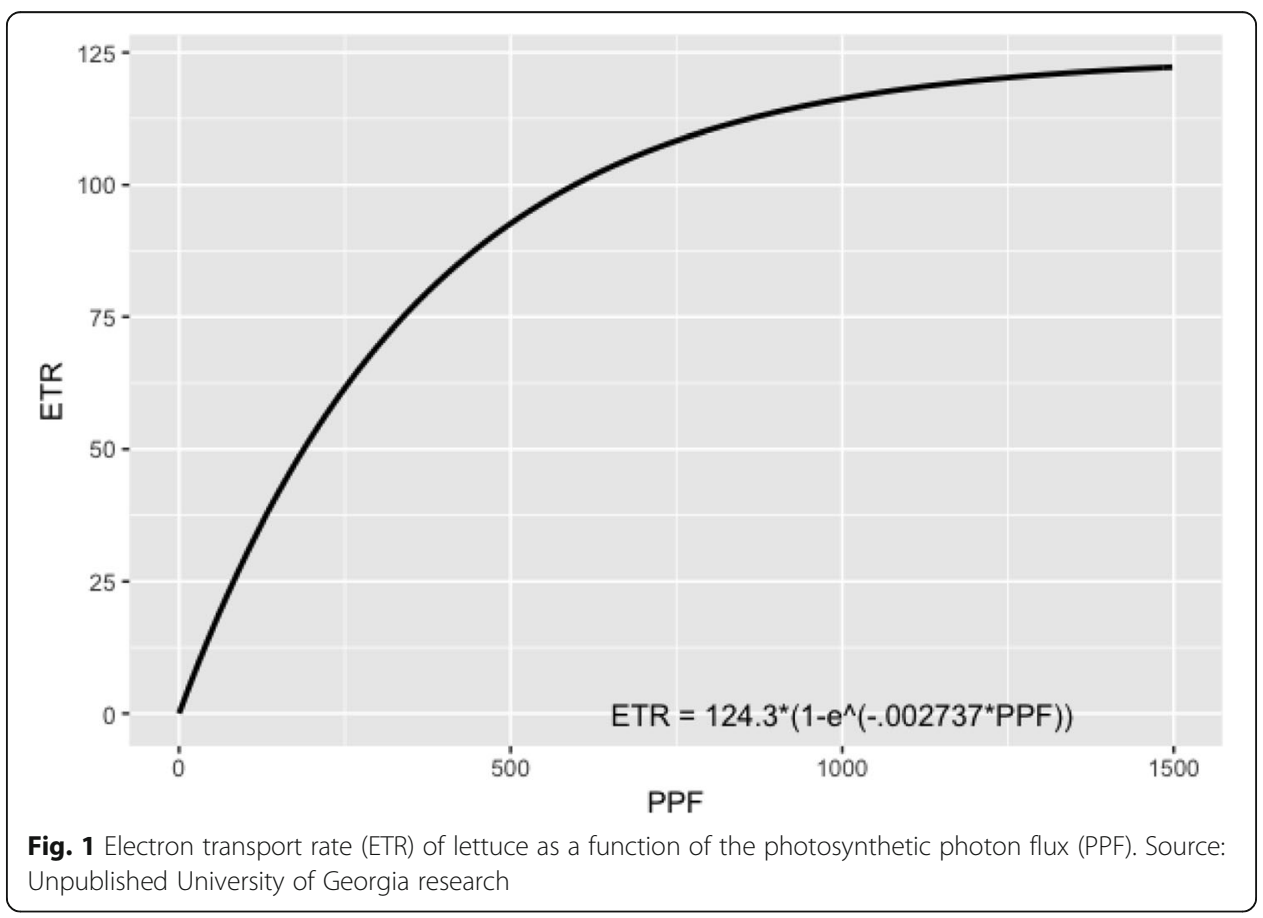


Tetr $=$ threshold ETR in $\mu$ moles $\mathrm{m}^{-2} \mathrm{~s}^{-1}$ to achieve D

Tppf $=$ threshold PPF in $\mu$ moles $\mathrm{m}^{-2} \mathrm{~s}^{-1}$ to achieve D

$t=$ seconds of operation per day of the greenhouse

$$
\begin{aligned}
& \text { Tetr }=\frac{D * 10^{6}}{t} \\
& \text { Tppf }=\frac{1}{b} \log \left(\frac{a}{a-\text { Tetr }}\right)
\end{aligned}
$$

\section{The innovation}

Supplementary lighting typically lacks intelligence and can be left on continually during the hours of operation, if not for an entire day. This means that energy can be wasted by providing more photons than a crop needs to optimize its daily growth.

A recent development in the context of commercial greenhouses is the replacement of HID lights with LED technology. LED technology has many advantages, such as smaller size (and thus easier to mount) than its HID predecessor and it is more energy efficient. More importantly, LEDs can be designed to produce light in the part of the spectrum that drives photosynthesis $(400-700 \mathrm{~nm}$ ), without producing infra-red radiation (which is not used for photosynthesis). LEDs are also fully dimmable, unlike HID lights, thus allowing growers to precisely control how much supplemental light is provided. For a LED light, the relationship between energy consumption and photons generated is essentially linear (National Electrical Manufacturers Association 2015), and we so assume in this research.

Leveraging this kind of lighting, a local company, Phytosynthetix, ${ }^{6}$ collaborated with the University of Georgia's Horticultural Physiology Laboratory to develop an innovation that could be transformative to the industry: adaptive LED lighting, which uses a built-in light intensity sensor to determine how much supplemental lighting to provide when natural lighting falls below a crop's threshold needs (van Iersel MW, Gianino D: An adaptive control approach for LED lights can reduce the energy costs of supplemental lighting in greenhouses, Submitted). Adaptive lighting provides just enough light to assure optimal crop growth and reduces electricity use compared to conventional control algorithms. The amount of supplemental light to provide can be based on the crop's physiological ability to use that light efficiently (see Fig. 1). This is an important innovation in greenhouse production as none of the available similar solutions take into consideration both natural light levels and crop-specific light use efficiency.

\section{Enhancing adaptive lighting by applying Energy Informatics}

The value of adaptive LED lighting can be increased by the application of Energy Informatics principles (Watson et al. 2010) to manage the lighting system to minimize electricity costs while meeting schedule constraints. The CEA version of the Energy Informatics framework (Fig. 2) incorporates all elements of an energy supply and demand system for greenhouses. We have taken the basic Energy Informatics framework, the yellow section of Fig. 2, and added details of the digital data streams (energy prices and solar radiation forecasts) and databases (plant details and production schedule) necessary to control the sensitized object (LED lighting). These four additional components illustrate how the core Energy Informatics information system can be extended for CEA. 


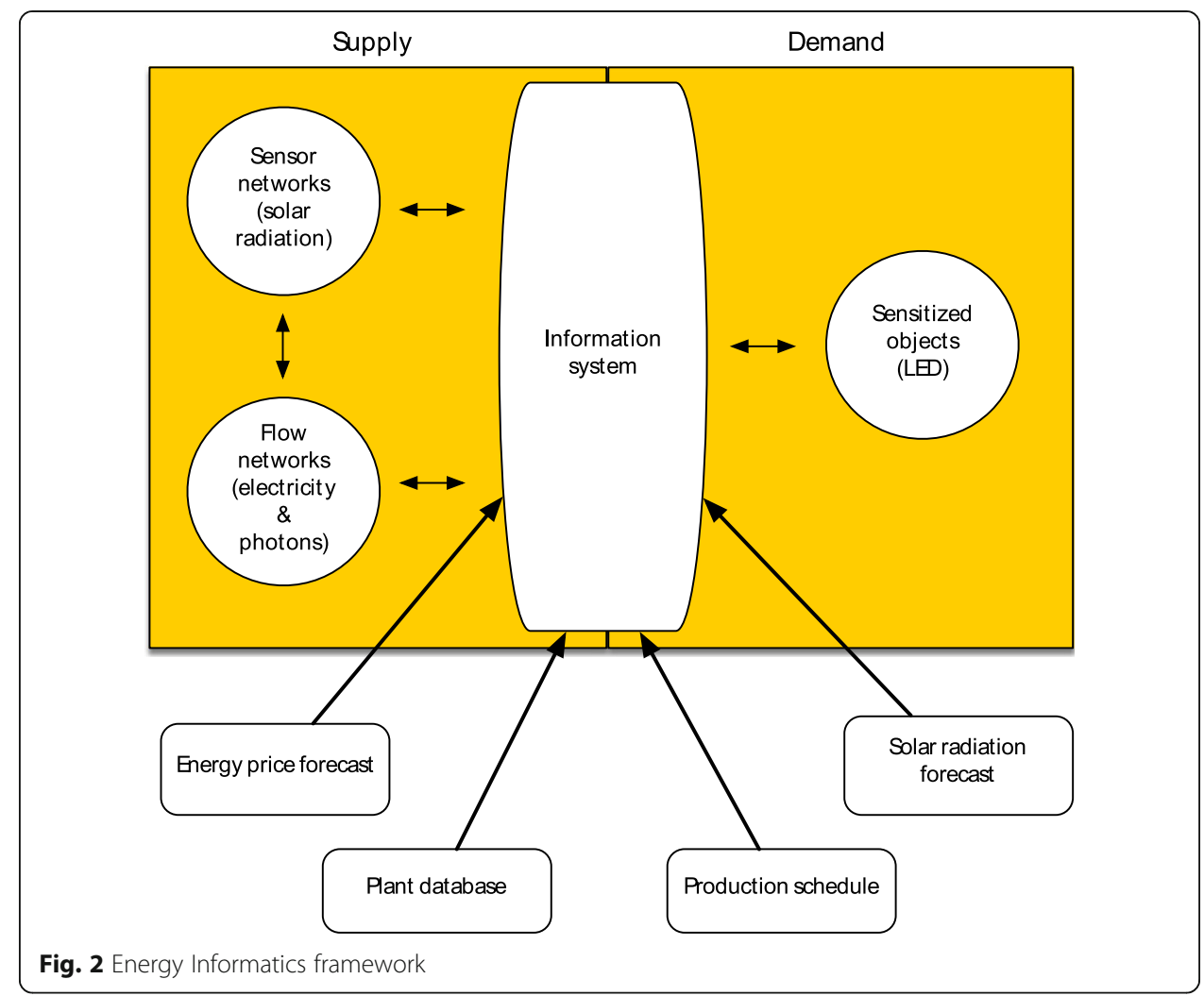

\section{Simulations}

To understand the advantage of adaptive LED lighting, while leveraging the Energy Informatics framework adapted to the context of CEA, we ran three simulations with increasing levels of sophistication. The first simulation leverages LED adaptive lighting. The second incorporates a daily decision, where the adaptive lights are turned off for the day when the expected daily solar radiation exceeds the ETR that optimizes growth. As to the third simulation, it leverages "within day" decision making, where the adaptive lights are turned off when the target solar radiation for the day has been achieved. Note that whereas Fig. 3 suggests an energy price forecast, we assumed a fixed energy cost for the time being. Moreover, rather than solar radiation forecasts, we used historical solar radiation data for a specific location and period. Last, for sake of simplicity in this first set of simulations, we did not consider the cost of production schedule delays.

The simulations were based on a 5-year period of growing lettuce in Athens, Georgia, with the following parameters:

$$
\begin{aligned}
& \mathrm{D}=3 \mathrm{~mol} \mathrm{~m}^{-2} \text { day }^{-1} \\
& t=20 \mathrm{~h} \mathrm{day}^{-1} \\
& \mathrm{a}=124.3 \mu \mathrm{mol} \mathrm{m}^{-2} \mathrm{~s}^{-1} \\
& \mathrm{~b}=.002737 \mathrm{~m}^{2} \mathrm{~s} \mu \mathrm{mol}^{-1}
\end{aligned}
$$

Electricity cost $=$ USD $.12 / \mathrm{kWh}$ (the rate charged by the local utility)

LED light $=600 \mathrm{~W}$

LED light range is $0-200 \mu$ moles $\mathrm{m}^{-2} \mathrm{~s}^{-1}$ 


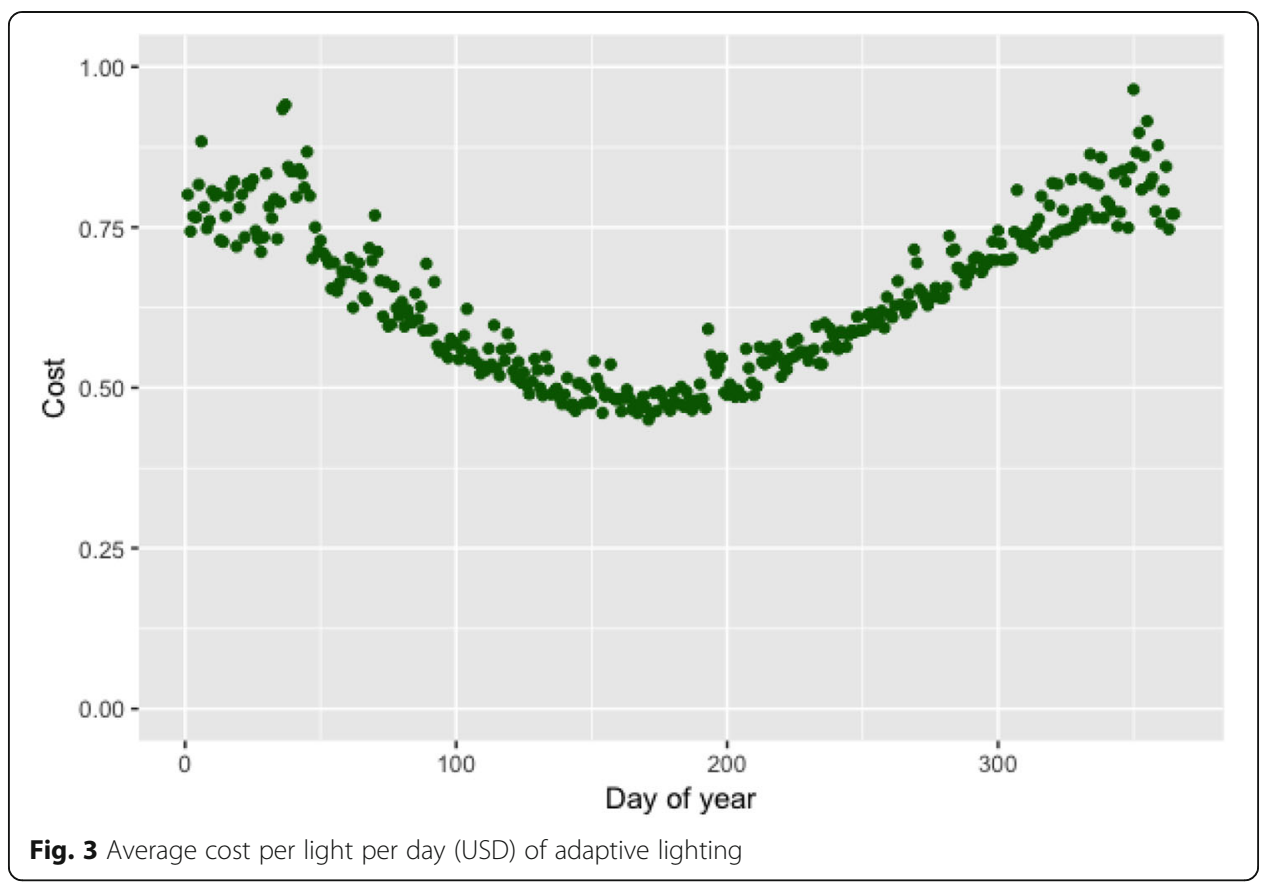

We assumed 70\% transmittance of the received solar radiation into the greenhouse. We compared the results of all three simulations to a baseline scenario, which involved non-adaptive LED lighting. This baseline scenario, along with the three simulations, are further detailed next. The greenhouse lighting layout assumes the use of 1,200 $600 \mathrm{~W}$ LED lights per hectare, capable of providing a PPF of $200 \mu$ moles $\mathrm{m}^{-2} \mathrm{~s}^{-1}$ with all lights on at full power.

\section{Baseline scenario: non-adaptive LED lighting}

Based on a recent survey of growers, ${ }^{7}$ we assume a typical greenhouse uses supplemental lighting for an average of $3.25 \mathrm{~h}$ per day $(9 \mathrm{~h}$ in winter, $2 \mathrm{~h}$ in fall and spring, and 0 in summer). The annual cost for this level of LED lighting is $.12 * 3.25 * 365.25 * 600 / 1000=$ USD 85.47 per light per year. A one hectare greenhouse needs about 1200 lights, so the cost would be USD 102,562 per year.

\section{Simulation\#1: Adaptive lighting}

This scenario assumes that the lights can be dimmed to any PPF between 0 and 200 $\mu$ moles $\mathrm{m}^{-2} \mathrm{~s}^{-1}$, and the relationship between energy use and PPF is linear between 0 and $600 \mathrm{~W}$. At its peak, adaptive lighting consumes the same energy as non-adaptive lighting. We use these parameters for the simulation.

Using solar radiation data collected in 10-min intervals in Athens, Georgia in 20102014, we simulate the use of adaptive lighting by computing Tppf for lettuce and setting the lights to maintain the mix of natural and supplemental lighting at this level. As the threshold for Tppf in this case is $149 \mu$ moles $\mathrm{m}^{-2} \mathrm{~s}^{-1}$, the adaptive lights were set to maintain this level. When there is sufficient natural light, the adaptive lights will consume $0 \mathrm{~W}$ and when there is complete darkness, they will consume $149 / 200 * 600=447 \mathrm{~W}$. 
The cost of operating the adaptive lighting in 2010-2014 to grow lettuce for $20 \mathrm{~h}$ per day is estimated to be USD 194.78 per light per year or for a one hectare greenhouse USD 233,738 per year. As expected, the lights are costlier to operate in winter than in summer (Fig. 3).

\section{Simulation\#2: daily decision making}

We simulated a model that would inform the grower whether to turn the adaptive lights off for the day when the forecast solar radiation for the day exceeds the total required to achieve an ETR of D moles $\mathrm{m}^{-2}$ day ${ }^{-1}$. Such an approach requires minimal investment and under a Software as a Service (SaaS) business model, the grower could be sent a text message on the recommended status of the adaptive lighting early each day.

The cost of operating the adaptive lighting under daily decision making in 2010-2014 to grow lettuce with $20 \mathrm{~h}$ of light per day is estimated to be USD 86.92 per light per year or for a one hectare greenhouse USD 104,302 per year, slightly above the baseline scenario. As to be expected, on many days there is no need to turn on the lights (Fig. 4).

\section{Simulation\#3: within day decision making}

A major shortcoming of a daily decision making model is that the forecasted radiation for a day could be just below the threshold, but the lights are turned on for the entire day.

Ideally, once the target for the day has been achieved, the lights should be turned off for the remainder of the day. We simulated such a model (Fig. 5), which shows that on some days the lights come on, but only for a short period with a corresponding lower cost.

The cost of operating the adaptive lighting under this approach in 2010-2014 to grow lettuce for $20 \mathrm{~h}$ per day is estimated to be USD 32.28 per light per year or for a one hectare greenhouse USD 38,732 per year, about one third of the baseline scenario.

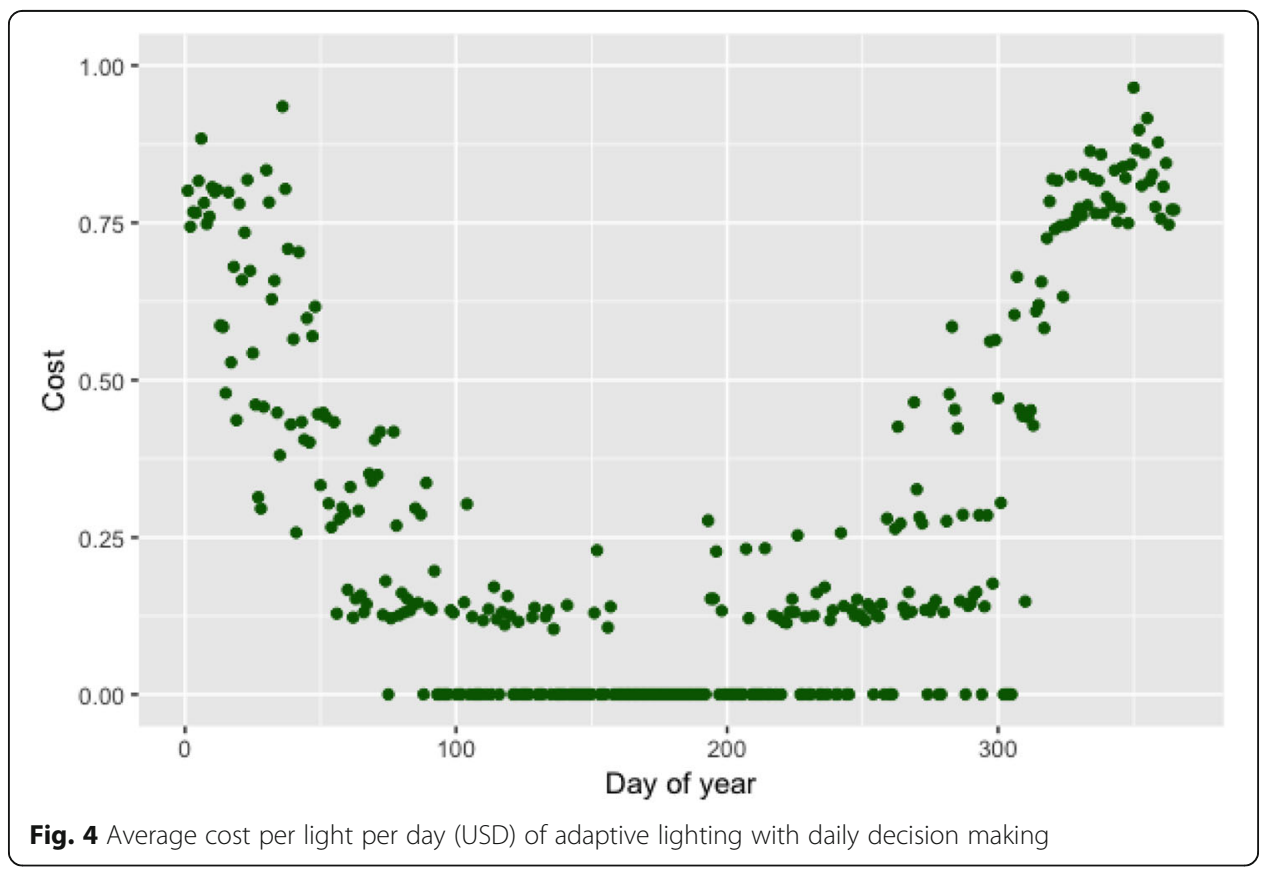




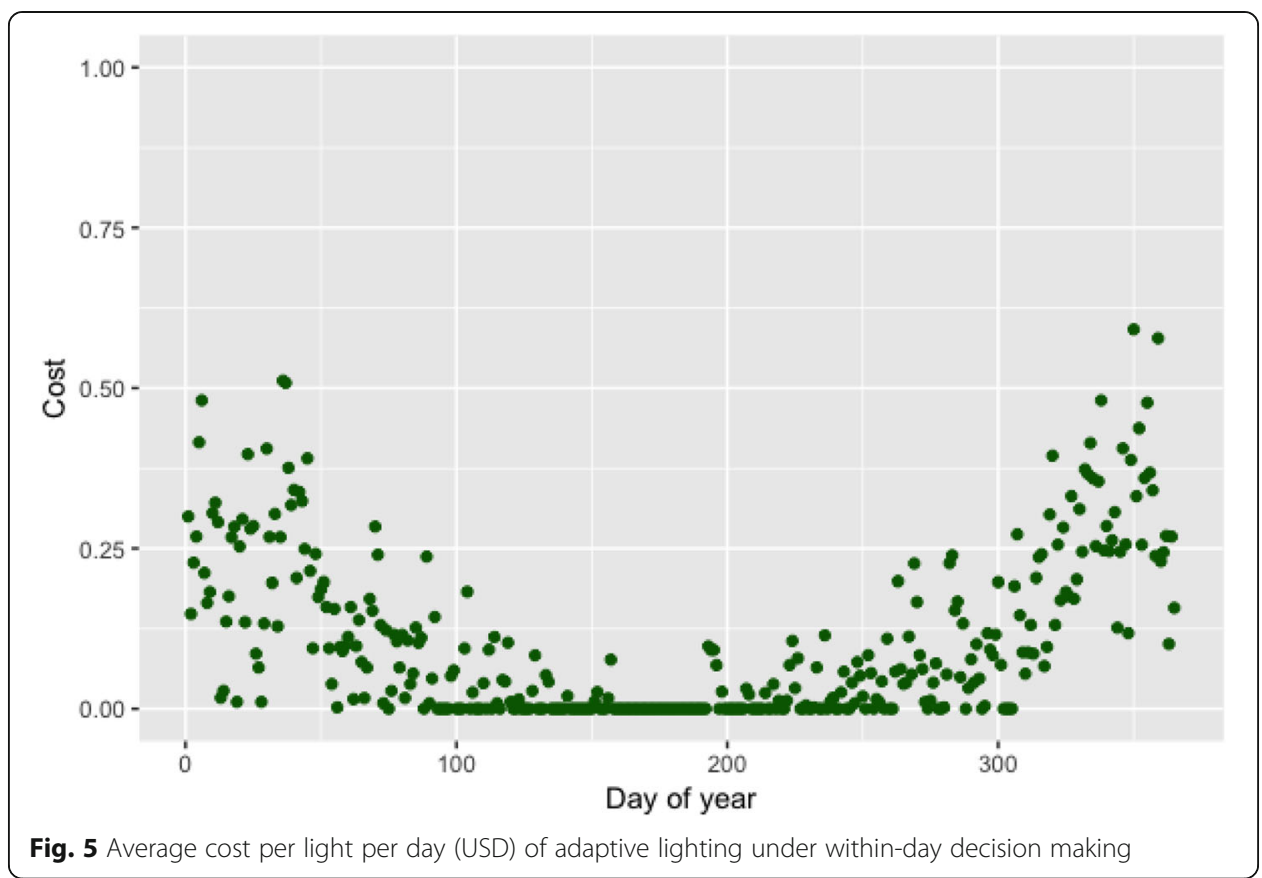

Under a Software as a Service (SaaS) business model, the within day approach requires that the grower invests in a lighting control system that can be controlled remotely. The controller would receive periodically a message to set the status (on or off) of the lights in the greenhouse. Thus, some of the energy savings will be lost to the operation and maintenance of a lighting control system, but we expect these to be minor compared to the energy use of the lights themselves.

\section{Execution}

The simulations were written in R, and the code is in four modules (see Additional file 1). The main module (simulation.R) loads modules to read the parameters for a simulation (parameters.R) and prepares data for the simulation (prepare.R). Another module (report.R) reports the results for each of the simulations discussed previously.

The simulations take advantage of R's vector-oriented operations for operating on data frames, and a typical run with 5 years of data takes a few seconds. In comparison, an earlier loop-based version of the model took 10 or so minutes to run.

The simulations require two binary input files, coded in R's feather format, ${ }^{8}$ which are described in Appendix.

\section{Return on investment}

The findings of the analysis show that only within day decision making will result in a reduction in total lighting cost compared to current manual practices (Table 1). Partial solutions, while they might deliver light precisely to ensure optimum plant growth, are likely to be subject to grower resistance because there is no cost advantage. Growers can save around $60 \%$ of the current cost of lighting by retrofitting their current LED lighting systems. Note that in the within day decision simulation, the lights are on half the time of the current manual or timer practice, but the electricity saving is higher 
Table 1 Simulation summary

\begin{tabular}{lll}
\hline Model & Cost per LED light per year (USD) & Average hours of LED light per day \\
\hline Current manual practice & 85.47 & 3.25 \\
Adaptive & 194.78 & 11.2 \\
Adaptive with daily decision & 86.92 & 5.09 \\
Adaptive within day decision & 32.28 & 1.69 \\
\hline
\end{tabular}

because the adaptive lighting generally does not operate the lights at full power. The energy savings are similar in magnitude to those reported for DynaGrow (Sørensen et al. 2016), however the two sites are at different latitudes, with Denmark in the mid $50 \mathrm{~s}^{\circ}$ and Athens, Georgia close to $34^{\circ}$, thus resulting in different light environments.

To compute the ROI, we conservatively estimate that the cost of equipping a greenhouse with a single solar radiation sensor, control software, and connecting existing LED lighting to the control software is USD 100 per light with a lifetime of 10 years, or USD 120,000 for a one-hectare greenhouse. The computed ROI is $68 \%$ for within day decision making. If we triple the cost estimate to USD 300 per light, then the ROI is $14 \%$. In effect, anything below USD 300 per light for retrofitting a greenhouse is financially sound and likely to provide additional benefits from exact contract fulfillment.

Although the prior simulations are based on a fixed energy cost of USD 0.12 per kWh, we wrote the code so that it can also process a file of historical real-time electricity prices. Such pricing is typically available only to large consumers (e.g., a factory or a university). In this case, the within day simulation determines which time periods during the day are the least expensive for operating the lights in order to meet the daily ETR goal.

\section{Limitations}

Solar radiation and electricity prices are dependent on local conditions. In this situation, based on 5 years of solar radiation data measured at the University of Georgia, the average solar radiation is $5.22 \mathrm{kWh} \mathrm{m}^{-2}$ day $^{-1}$. The University is in the sunny south-east of the US, and thus our results show the advantage of this additional solar energy. Also, the region has some of the cheaper electricity in the US. The US average is USD $.13 \mathrm{kWh}$, with a range of USD .10 to $.29 \mathrm{kWh}$. Georgia, at USD .125, is towards the lower end of this range. ${ }^{9}$ If the simulations had been based on solar radiation in the north-east of the US, for example, savings would be different because of less solar radiation, more required supplemental lighting, and higher electricity prices. In essence, our results should be interpreted as being appropriate for a relatively sunny region with relatively cheap electricity. Our simulation framework can easily be used to simulate different locations.

The main purpose of these simulations is to show the potential of using solar radiation and electricity cost forecasts to reduce the cost of operating a greenhouse. However, rather than forecasts, we have simulated the perfect information situation where electricity prices and solar radiation can be precisely predicted. As most greenhouses are too small to presently avail themselves of real-time pricing, treating the price of electricity as fixed is appropriate. Thus, in moving beyond perfect information, the focus needs to be on solar radiation forecasting.

It can be argued that simulations represent a simplified reality. However, such simplicity means that they can be readily explained to a grower, which in turn is likely to increase the likelihood of adoption. The simple decision rules are very effective in reducing cost, 
and additional complexity is unlikely to be required or produce significant additional savings. Furthermore, the second and third simulations can be easily implemented from a central source using a SaaS model, which lowers the cost for adoption and maintenance.

\section{Future research}

As mentioned earlier, by using historical data, we assume perfect information. Thus, the next step is to simulate the effects of solar radiation forecasts with varying degrees of accuracy to determine the sensitivity of the findings to forecast precision. We speculate that sensitivity will be low for two reasons: (1) the goal is to determine whether or not to turn on adaptive lighting for a set period, such as $10 \mathrm{~min}$; and (2) a multi-period forecast for the remainder of day can be continually adjusted throughout the day.

The essential problem, whether to turn the lights on or off for a set period would seem to be a simpler problem than trying to forecast the level of radiation for the same period. Intelligent adaptive LED lighting provides the precision to ensure plants receive the necessary photons to meet growth goals, provided the LED light is on. We plan to build two forecasting models, one for the binary decision of LED light on or off and the second to forecast radiation levels. Based on prior research, it would appear that a neural network (Wollsen and Jørgensen 2015) with allowance for autocorrelation is appropriate for radiation level forecasting, whereas logistic regression might be suitable for the binary decision.

The goal is to deliver sufficient photons each day for a plant to reach its daily growth needs. Throughout a day, the forecast system must continually adapt to meet this target. As the forecast period becomes shorter, then adaption can be faster. Thus, one of the issues is to simulate the precision of the forecasting system to the length of the decision period (e.g., 5 versus $20 \mathrm{~min}$ ). As we expect the computing cost of each forecast to be quite small and the communication cost of the on/off decision to each light to also be small, the selected time period might make little financial difference for an individual grower given the gains achieved by efficient management of LED usage. Nevertheless, these assumptions need to be validated.

Since natural light conditions vary greatly among locations, it will also be important to run simulations for a range of regions, especially those where greenhouses most commonly use supplemental light, like Canada, the Northern US, and Northwestern Europe.

We need to elaborate the simulation model to embrace more decision parameters, such as those considered in prior research (e.g., Clausen et al. 2015; Kjaer et al. 2011, 2012; Mærsk-Møller and Jørgensen 2011; Markvart et al. 2007; Rytter et al. 2012; Sørensen et al. 2011; Sørensen et al. 2016), and apply photosynthesis theories that take account of light wavelength and the capability of controlling the wavelength of LED lighting.

There is much to learn about LED lighting because it is a relatively recent introduction to the greenhouse environment. It enables control over spectral power distribution, optical intensity distribution, form factor, and active color tuning. It can be used, as in this study, to tailor light to a specific crop to improve productivity by controlling precisely the photons delivered to ensure threshold needs for growth are met. Other aspects of plant growth such as height, bushiness, and color or nutritional content are potential areas for research (Pattison 2017). This research simulates LED usage approaches to minimize electricity cost by applying prior research on threshold curves. It assumes that if a plant 
receives sufficient photons, or the right amount of light, to meet daily growth needs, the quality of the crop will be of commercial standard. Assessment of this assumption is a topic for future research, and the power of simulation is to help identify opportunities for fruitful research.

\section{Conclusion}

This initial study of the application of Energy Informatics to CEA illustrates the potential to considerably reduce the energy required to operate a greenhouse. Our plans are to extend the research to cover other commercial crops (e.g., red leaf lettuce, spinach, basil, tomatoes, and cucumbers) as well as ornamental species, including high-light crops (roses, petunias, and marigolds) and low light crops (impatiens, begonia, and hellebore). Moreover, we plan to consider four diverse regions of the continental US, because solar radiation varies greatly across this region (i.e., from an average of 3.0 to over $6.5 \mathrm{kWh} \mathrm{m}^{-2}$ day $\left.^{-1}\right) .{ }^{10}$

This research shows the value of the Energy Informatics framework for addressing practical problems. It helps scientists communicate with growers by focusing on the three elements that are necessary for an information system to manage an energy flow. In the case of CEA, engaging growers will be critical to adoption of information systems augmented adaptive lighting. It also demonstrates the potential for using simulation to explore the effects of energy management options.

The Lawrence Livermore National Laboratory publishes annually an infographic on energy use in the U.S. The 2016 version estimates that about two thirds of the energy generated is wasted. ${ }^{11}$ The application of Energy Informatics thinking to CEA illustrates that in some areas of the economy, significant energy efficiency gains can be achieved with simple solutions. We expect that CEA is not an exception and the launching of Energy Informatics can potentially alert more scholars and practitioners to the synergistic gains of integrating engineering advances, such as adaptive lighting, and information systems to achieve higher levels of energy efficiency. Creating a sustainable society is dependent on engineering and IS scholars combining minds and knowledge.

\section{Endnotes}

${ }^{1}$ https://www.businesswire.com/news/home/20170713006114/en/

Global-Greenhouse-Horticulture-Market-2017-2021-Key-Geographies

${ }^{2}$ https://www.zionmarketresearch.com/sample/smart-greenhouse-market

${ }^{3}$ Which can be further subdivided into two types, metal halide and high-pressure sodium.

${ }^{4}$ Compounds of carbon, hydrogen, and oxygen. Sucrose is $\mathrm{C}_{12} \mathrm{H}_{22} \mathrm{O}_{11}$.

${ }^{5} 1 \mathrm{~mol}=6.022 \times 10^{23}$ (Avogadro's constant) photons or electrons.

${ }^{6}$ http://phytosynthetix.com

${ }^{7}$ http://stateofindoorfarming.agrilyst.com

${ }^{8}$ https://blog.rstudio.com/2016/03/29/feather/

${ }^{9}$ https://www.eia.gov/electricity/monthly/epm_table_grapher.php?t=epmt_5_6_a

${ }^{10} \mathrm{https} / / /$ azsolarcenter.org/images/articles/az/national_photovoltaic_map_2012-01.jpg

${ }^{11}$ https://flowcharts.llnl.gov/commodities/energy 


\section{Appendix}

\section{Data availability}

electricity.feather

https://www.dropbox.com/s/dxvep9kglspy47n/electricity.feather?dl=0

A binary file containing a timestamp and electricity price in cents per kWh. Measurements are hourly.

\section{radiation10.feather}

https://www.dropbox.com/s/ozvtrfudnymmug8/radiation10.feather?dl=0

A binary file containing a timestamp and incident solar radiation in Watts $\mathrm{m}^{-2} \mathrm{~s}^{-1}$.

Measurements are for every $10 \mathrm{~min}$, and derived from a file of measurements made every $2 \mathrm{~min}$.

These files must be stored in an $\mathrm{R}$ project working directory along with the $\mathrm{R}$ modules. The location of this working directory must be specified in the second line of parameter.R

\section{Additional file}

Additional file 1: $\mathrm{R}$ code. (TXT $6 \mathrm{~kb})$

\section{Acknowledgements}

Only the authors listed on the manuscript contributed towards the article.

Funding

This research was supported by a University of Georgia Presidential seed grant.

Authors' contributions

Drs. M-CB and RTW were responsible for the Energy Informatics simulation. Dr. MWvl provided the data on the saturation model for lettuce and details of plant physiology relevant for the simulation. All authors read and approved the final manuscript.

Competing interests

The authors declare that they have no competing interests.

\section{Publisher's Note}

Springer Nature remains neutral with regard to jurisdictional claims in published maps and institutional affiliations.

\section{Author details}

${ }^{1}$ Department of Management Information Systems, University of Georgia, Athens, GA 30602-1575, USA. ²Department of Horticulture, University of Georgia, Athens, GA 30602-7273, USA.

Received: 31 January 2018 Accepted: 11 June 2018

Published online: 02 August 2018

References

Aaslyng JM, Lund JB, Ehler N, Rosenqvist E (2003) IntelliGrow: a greenhouse component-based climate control system. Environ Model Softw 18(7):657-666

Both AJ, Albright LD, Langhans RW, Reiser RA, Vinzant BG (1994) Hydroponic lettuce production influenced by integrated supplemental light levels in a controlled environment agriculture facility: experimental results. Paper presented at the III International Symposium on Artificial Lighting in Horticulture. p. 418

Clausen A, Maersk-Moeller HM, Soerensen JC, Joergensen BN, Kjaer KH, Ottosen CO (2015) Integrating commercial greenhouses in the smart grid with demand response based control of supplemental lighting. Paper presented at the International Conference Industrial Technology Management Science (ITMS 2015)

Food and Agriculture Organization of the United Nations (2009) Global Agriculture Towards 2050. Retrieved 19 Aug 2016, from Food and Agriculture Organization of the United Nations: http://www.fao.org/fileadmin/templates/wsfs/ docs/Issues_papers/HLEF2050_Global_Agriculture.pdf. Accessed 18 June 2018

Gholami R, Watson RT, Molla A, Hasan H, Bjørn-Andersen N (2016) Information systems solutions for environmental sustainability: how can we do more? J Assoc Inf Syst 17(8):521

Holdren JP (2009) Energy for change: introduction to the special issue on Energy \& Climate. Innov Technol Gov Glob 4(4):3-12

Kjaer KH, Ottosen CO, Jørgensen BN (2011) Cost-efficient light control for production of two campanula species. Sci Hortic 129(4):825-831 
Kjaer KH, Ottosen CO, Jørgensen BN (2012) Timing growth and development of Campanula by daily light integral and supplemental light level in a cost-efficient light control system. Sci Hortic 143:189-196

Mærsk-Møller HM, Jørgensen BN (2011) A software product line for energy-efficient control of supplementary lighting in greenhouses. Paper presented at the The International Conference on Green Computing

Magnin C (2016) How Big Data Will Revolutionize the Global Food Chain. Retrieved 19 Aug 2016, from McKinsey \& Company: http://www.mckinsey.com/business-functions/digital-mckinsey/our-insights/how-big-data-willrevolutionize-the-global-food-chain?cid=digistrat-eml-alt-mip-mck-oth-1608. Accessed 18 June 2018

Malhotra A, Melville NP, Watson RT (2013) Spurring impactful research on information systems for environmental sustainability. MIS Q 37(4):1265-1274

Markvart J, Kalita S, Nørregaard Jørgensen B, Mazanti Aaslyng J, Ottosen CO (2007) IntelliGrow 2.0-A greenhouse component-based climate control system. Paper presented at the International Symposium on High Technology for Greenhouse System Management: Greensys 2007801

National Electrical Manufacturers Association (2015) Energy Savings with Fluorescent and LED Dimming.). LSD $73-2015$. http://www.nema.org/Standards/SecureDocuments/NEMALSD\%2073-2015\%20WATERMARKED.pdf. Accessed 18 June 2018

Pattison (2017) Foreword. In: Gupta SD (ed) Light emitting diodes for agriculture: smart lighting. Springer, Singapore

Rytter M, Sørensen JC, Jørgensen BN, Körner O (2012) Advanced model-based greenhouse climate control using multiobjective optimization. Paper presented at the IV International Symposium on Models for Plant Growth, Environmental Control and Farm Management in Protected Cultivation- 957

Science Illustrated (2011) CEA. Science Illustrated, Feb. https://en.wikipedia.org/wiki/Controlled-environment_agriculture. Accessed 18 June 2018

Sørensen JC, Jørgensen BN, Klein M, Demazeau Y (2011) An agent-based extensible climate control system for sustainable greenhouse production. Paper presented at the International Conference on Principles and Practice of Multi-Agent Systems

Sørensen JC, Kjaer KC, Ottosen CO, Jørgensen BN (2016) DynaGrow-Multi-Objective Optimization for Energy Costefficient Control of Supplemental Light in Greenhouses. Paper presented at the IJCCI (ECTA)

Watson RT, Boudreau MC (2011) Energy informatics. Green ePress, Athens

Watson RT, Boudreau MC, Chen AJ (2010) Information systems and environmentally sustainable development: energy informatics and new directions for the IS community. MIS Q 34(1):23-38

Wollsen MG, Jørgensen BN (2015) Improved local weather forecasts using artificial neural networks. Paper presented at the Distributed Computing and Artificial Intelligence, 12th International Conference

\section{Submit your manuscript to a SpringerOpen ${ }^{\circ}$ journal and benefit from:}

- Convenient online submission

- Rigorous peer review

Open access: articles freely available online

- High visibility within the field

- Retaining the copyright to your article 